\title{
Updates on the clinical diagnosis and management of ocular sebaceous carcinoma: a brief review of the literature
}

This article was published in the following Dove Press journal:

OncoTargets and Therapy

\author{
Yangfan $\mathrm{Xu}^{1,2, *}$ \\ Fang $\mathrm{Li}^{1,2, *}$ \\ Renbing Jia ${ }^{1,2}$ \\ Xianqun Fan ${ }^{1,2}$ \\ 'Department of Ophthalmology, \\ Shanghai Ninth People's Hospital, \\ Shanghai Jiao Tong University School \\ of Medicine, Shanghai, People's \\ Republic of China; ${ }^{2}$ Shanghai Key \\ Laboratory of Orbital Diseases \\ and Ocular Oncology, Shanghai, \\ People's Republic of China \\ *These authors contributed equally \\ to this work
}

\begin{abstract}
Ocular sebaceous carcinoma (SC) is an exceedingly rare but aggressive malignancy that can impair patients' visual acuity or even cause tumor-specific mortality. This tumor usually mimics chronic benign eyelid lesions, thus leading to delayed diagnosis, thereby causing high recurrence and metastasis. Ophthalmologists should be more aware of SC in order to offer correct diagnosis and treatment at the onset of symptoms. Prompt surgical excision with frozen section margin control is the mainstay of SC management after patient evaluation and accurate biopsy. Mohs micrographic surgery has been associated with better tumor control outcomes than wide local excision. Radiation therapy should be considered as adjuvant treatment for locally advanced (stage T3a or higher) or high-risk (pagetoid spread) SC, nodal metastasis, or palliative care. Cryotherapy and topical chemotherapy are used for pagetoid spread. Targeted therapy has an emerging role in more complicated cases. For lymph node and distant metastasis, combination treatments should be provided, including lymph node and neck dissection, radiation therapy, systemic chemotherapy, and even orbital exenteration. The rarity of ocular SC precludes a comprehensive perspective on standard treatment. This paper offers a brief review of recent advances in the clinical diagnosis and management of ocular SC based on current scientific literature.
\end{abstract}

Keywords: sebaceous carcinoma, periocular cancers, therapy, Mohs micrographic surgery

\section{Introduction}

Sebaceous carcinoma (SC) is a rare malignancy that is challenging even for experienced ophthalmologists and dermatologists to recognize and cure successfully. Early diagnosis and prompt surgery may improve treatment outcomes. Advances have been achieved over the past several decades even though the current literature contains only small- to medium-sized case reports. This review summarizes the demographics, etiology, clinical presentation, and pathology of ocular SC with a special emphasis on the diagnosis and management.

\section{Incidence and demographics}

Xianqun Fan

Department of Ophthalmology,

Shanghai Ninth People's Hospital

Shanghai Jiao Tong University School of

Medicine, 639 Zhi Zao Ju Road

Shanghai 2000II, People's Republic

of China

Tel +862163135606

Fax +86216313 7148

Email renbingjia@sjtu.edu.cn;

fanxq@sjtu.edu.cn
$\mathrm{SC}$ is frequently regarded as either ocular or extraocular. SC occurs more frequently in the head and neck, and the ocular region is the most common site, accounting for $34.5 \%-59 \%$ of cases. ${ }^{1-5}$ However, the latest study on the incidence and survival of SC in the USA reported a significantly lower ratio of ocular SC $(25.8 \%) .{ }^{6} \mathrm{SC}$ is considered a relatively rare tumor of the eyelid, accounting for approximately $5 \%$ cases of malignant eyelid tumors in the $\mathrm{USA}^{7}$ and $7.9 \%$ in Taiwan. ${ }^{8}$ It is the third most common eyelid malignancy after basal cell carcinoma (BCC) and squamous 
cell carcinoma (SCC). In Asian populations, SC is generally considered to be as prevalent as or more common than BCC, accounting for $28 \%-60 \%$ of all eyelid malignancies. ${ }^{7}$ However, Dasgupta et $\mathrm{al}^{1}$ found a significantly higher incidence of SC among whites (2.03 per million) than Asian/Pacific Islanders (1.07 per million) in the USA. The most likely explanation for this is the relatively low incidence of other eyelid skin tumors rather than Asian predominance.

Ocular SC is a disease of elderly patients, especially females, with mean patient age ranging from 70 to 72 years. ${ }^{6,9,10}$ However, this gender association has been questioned, as a review of 1,349 US cases in the Surveillance, Epidemiology, and End Results database found a slight predominance of men $(54 \%){ }^{1}$

\section{Ocular origins}

Tumors of sebaceous glands in the ocular region originate in the meibomian glands, glands of Zeis, caruncle, and skin of the eyebrow. ${ }^{11}$ The upper eyelid is the most common site of $\mathrm{SC}$ due to the dense concentration of meibomian glands. ${ }^{12,13}$ Lesions involving both the lower and upper eyelid occur simultaneously in $1 \%-6 \%$ of patients. ${ }^{14}$ In exceedingly rare cases, the lacrimal gland has not only been shown to be a target of tumor invasion but also a source of primary SC with higher mortality than other locations. ${ }^{15}$ Another aggressive feature of SC is multicentricity, which can be detected in a small percentage of patients with a high risk of local recurrence. ${ }^{9,12,16}$ In addition, intracranial involvement can be seen in rare cases. ${ }^{7,17}$

\section{Etiology}

Despite the aggressive nature and poor outcomes of SC, little is known about its etiology and tumorigenesis. Possible risk factors for SC, except for the older patient age and female sex, include prior irradiation, immunosuppression, genetic predisposition for Muir-Torre syndrome, ${ }^{18,19}$ production of nitrosamines, and photosensitization from previous diuretic use. ${ }^{5,11}$

An association between SC and retinoblastoma exists, but the relationship is unclear. It has been reported that SC possesses higher morbidity in patients with hereditary retinoblastoma who received local irradiation at an early age. SC typically occurs in the irradiated field after a 5- to 15-year delay. In contrast, SC can also occur in patients with retinoblastoma without any history of prior radiation. ${ }^{20}$

As for genetic changes, p53 dysregulation has been observed in a large proportion of patients. ${ }^{21,22}$ Human epidermal growth factor receptor 2 (HER2) amplification ${ }^{23}$ and epigenetic changes, such as hypermethylation of the CDKN2A promoter, ${ }^{24}$ have more recently been implicated in the development of SC. The latter finding has been correlated with ocular SC onset at an earlier age. Based on the results of whole-exome next-generation sequencing of $27 \mathrm{SCs}$, Tetzlaff et $\mathrm{al}^{25}$ found 139 nonsynonymous somatic mutations in ocular SCs with TP53, RB1, PIK3CA, PTEN, ERBB2, and NF1 as the most common mutations. These mutations were predicted to activate the PI3K signaling cascade, which implicates $\mathrm{PI} 3 \mathrm{~K}$ pathway activation as an important driver in ocular SC.

\section{Clinical manifestations and differential diagnosis}

Clinically, SC of the eyelid may manifest as a painless solitary nodule or diffuse pseudo inflammation. The more common painless solitary nodule presents as a firm subcutaneous lesion that arises in and is fixed to the tarsus, or it appears in the eyelid margin when it arises from the gland of Zeis. In such cases, SC may mimic chalazion. However, SC eventually causes loss of cilia, which can be differentiated from chalazion. ${ }^{5}$ Special care should be paid to elderly individuals. Their increased eyelid skin laxity may disguise an ocular SC mass as a chalazion, and this patient group is less likely to contact a doctor for apparently benign eyelid swelling. ${ }^{9}$ The second most common presentation of SC is diffuse thickening of the eyelid, which may involve the fornical and bulbar conjunctiva. In these cases, the patient may be misdiagnosed with persistent unilateral blepharitis or conjunctivitis at onset because of the pagetoid spread. ${ }^{5}$

Pagetoid spread refers to intraepithelial (in situ) disease in the conjunctiva, even to the cornea ${ }^{26}$ in a noncontiguous fashion. The rates of pagetoid spread have been reported as $26 \%-51 \% .^{9,12,27}$ The most common symptom and sign of SC with pagetoid invasion is ocular irritation and diffuse eyelid thickening. Pagetoid invasion generally carries a higher risk of orbital exenteration, recurrence, or tumor-related metastases, ${ }^{4,28}$ but contradictory opinions also exist. ${ }^{16,29,30}$

Furthermore, ocular SC may be clinically indistinguishable from SCC, BCC, intratarsal keratinous cyst, or other rare eyelid lesions. ${ }^{10,12,31}$ In conclusion, clinicians must consider the diagnosis of SC when a patient has a recurrent, atypical, and/or treatment-resistant lesion that is originally presumed to be benign..$^{9,17}$

\section{Histology and pathology}

The diagnosis of SC largely relies on primary excisional biopsy during the management. 
When the lesion is small and circumscribed, complete excision is strongly suggested before histopathologic verification, whereas relatively more extensive lesions require incisional biopsy. ${ }^{5}$ It has been reported that the majority of UK centers perform full-thickness eyelid biopsy. ${ }^{9}$ If diffuse involvement of palpebral and bulbar conjunctiva is suspected, multiple conjunctival map biopsies are recommended. ${ }^{5}$ Map biopsies scheduled at the time of wide excision with permanent section control rather than frozen sections may improve the reliability of complete excisions. ${ }^{16}$ Some have advocated that conjunctival map biopsy should be the primary procedure in all suspected cases. ${ }^{9}$ Unfortunately, $\mathrm{SC}$ is often misdiagnosed on initial biopsy and may require multiple biopsies or special stains before a definitive diagnosis can be made..$^{10,17}$

Histopathologically, SC can be recognized by the following 4 patterns: lobular, comedocarcinoma, papillary, and mixed. ${ }^{5}$ An extended evaluation of hematoxylin and eosin stains remains essential, but immunohistochemistry has shown an unequivocal profile in ocular SC. Immunostaining has largely replaced lipid and fat staining on fresh frozen sections and is widely applied to differentiate SC from other malignant neoplasms. ${ }^{16}$ Tumor cells stain with epithelial membrane antigen, cytokeratin, Ber-EP4, cyclooxygenase 2, peroxisome proliferator-activated receptor $\gamma$ and androgen receptor. And SCs are negative for carcinoembryonic antigen, $\mathrm{S} 100$ protein, or gross cystic disease fluid protein. ${ }^{32,33}$ Compared to benign sebaceous proliferations, SC expresses increased p53 and Ki-67 levels (proliferation markers) and decreased bcl-2 and p21 levels (antiapoptotic markers). ${ }^{34}$ Adipophilin shows an annular staining of lipid granules in immature sebaceous cells in contrast to a more granular staining pattern in BCC and SCC. ${ }^{33}$ In addition, a provisional classification of $\mathrm{SC}$ based on hormone receptor expression and HER2 status has been recently proposed. Expression of HER2 protein was found in 33.8\% of cases and was associated with better outcomes with borderline significance $(P=0.060) .35$

However, the high rate of interobserver variability cannot be neglected. Incorrect histopathological interpretations have been reported in $23 \%-77 \%$ of cases, and these misinterpretations may be due to tumor rarity, low clinical suspicion, and pathologists' lack of familiarity with the histological features of SC..$^{9,36}$

\section{Management}

The management of SC is largely dependent on its histopathologic type and disease stage according to the American Joint Committee on Cancer seventh edition TNM guidelines
Table I Treatment options for ocular SC

\begin{tabular}{|c|c|}
\hline $\begin{array}{l}\text { Treatment } \\
\text { option }\end{array}$ & Indication \\
\hline MMS & $\begin{array}{l}\text { Appropriate for SC in all locations (except the inner, } \\
\text { outer canthus and cases with orbital involvement), } \\
\text { the best choice for removing SC on the eyelid }\end{array}$ \\
\hline WLE & Mainstay of SC standard treatment \\
\hline Exenteration & SC with extensive conjunctival or orbital involvement \\
\hline $\begin{array}{l}\text { Radiation } \\
\text { therapy }\end{array}$ & $\begin{array}{l}\text { Adjuvant treatment for locally advanced or high-risk } \\
\text { periorbital SC, perineural invasion, nodal metastasis, } \\
\text { or palliative treatment }\end{array}$ \\
\hline $\begin{array}{l}\text { Cryotherapy } \\
\text { and topical } \\
\text { chemotherapy }\end{array}$ & $\begin{array}{l}\text { Pagetoid spread to the conjunctiva or cornea, } \\
\text { adjuvant therapy for residual SC in situ, and for } \\
\text { patients who prefer conservative approaches }\end{array}$ \\
\hline
\end{tabular}

Abbreviations: MMS, Mohs micrographic surgery; SC, sebaceous carcinoma; WLE, wide local excision.

for eyelid carcinomas after complete clinical evaluation. A brief summary of major treatment options is provided (Table 1).

Therefore, treatment needs to be tailored in each case based on the extent of the tumor and the specific demands of the patient. Moreover, combination therapy is currently being promoted, especially in advanced cases. Radiotherapy, cryotherapy, topical chemotherapy, amniotic membrane grafting, flap reconstruction, and other techniques are followed by surgical excision to achieve the best treatment effect. ${ }^{5,13,16,37,38}$

\section{Patient evaluation}

Patients with suspected eyelid malignancies should undergo a thorough medical history inquiry with special care about a history of prior skin cancer, sun exposure, radiation exposure, and immune status. Meanwhile, a complete ocular adnexal examination is indispensable. Baseline external photographs or slit-lamp photographs are useful for documentation and future comparison. ${ }^{30}$

Considering that no standardized imaging or staging guidelines currently exist, imaging studies and additional work up for regional or distant disease should be symptom driven. Based on the suspicion of orbital invasion or a risk of lymph node metastasis, examinations, including orbital computed tomography or MRI, ultrasonography of the parotid, submandibular, and cervical nodes, and fine-needle aspiration biopsy of suspicious lymph nodes, should be considered. For cases associated with a risk of distant metastasis, baseline chest radiography or computed tomography should be performed. ${ }^{30}$

The identification of high- and low-risk features in ocular $\mathrm{SC}$ based on clinical evaluations enables a stratified approach to treatment. 


\section{Sentinel lymph node biopsy (SLNB)}

The role of SLNB in ocular SC is controversial. Application of SLNB has been found to be positive in ocular SC. ${ }^{17,39}$ The rate of regional lymph node metastasis is reported to be as high as $10 \%-28 \%$ in ocular SC. ${ }^{20,27,40}$ However, 2 other retrospective studies demonstrated low rates of regional metastasis at $1.3 \%$ and $4.4 \% .^{1,4}$ The large-scale absence of definitive records of patients' lymph node status in these studies may explain the statistical diversity. These researchers recommend SLNB or at least strict regional lymph node surveillance for patients with tumors of $\mathrm{T} 2 \mathrm{~b}$ or worse or $10 \mathrm{~mm}$ or more in their greatest dimension., ${ }^{4,27}$

However, the Multicenter Selective Lymphadenectomy Trial II found disease-specific survival to be similar at 73 months in patients who underwent complete lymphadenectomy immediately after positive SLNB compared to those who did not. ${ }^{41}$ Thus, additional rigorous studies are required to verify the utility of SLNB, and an ongoing clinical trial will possibly provide some insights. ${ }^{42}$

\section{Mohs micrographic surgery (MMS)}

MMS consists of the removal and extemporaneous analysis of every skin stratum until disease-free margins are identified. The advent of MMS has given ophthalmologists a reliable method for intraoperative assessment of surgical margins while ensuring maximal preservation of healthy tissue. ${ }^{17}$ Based on MMS appropriate use criteria, MMS is deemed appropriate for SC in all locations, except the inner, outer canthus and cases with orbital involvement. According to a series of retrospective studies from 2001 to 2017, which is reviewed and summarized as below (Table 2), MMS is associated with lower local recurrence rates $(6.4 \%-11 \%)$ than wide local excision $(11 \%-36 \%){ }^{16,43}$

Overall, MMS has been associated with very good outcomes for tumor control and should be considered for all patients with ocular SC. ${ }^{49}$ The rarity of this tumor precludes large-scale comparative studies, but the existing studies may have provided some clues. Circumstances may be different in the UK, where MMS is not frequently undertaken in ophthalmic/oculoplastic services.

\section{Wide local excision (WLE)}

If tissue-sparing techniques are not available, wide surgical excision with margins of normal-appearing tissue at least $5 \mathrm{~mm}$ are preferred. ${ }^{7,17}$ Scheduled map biopsies at the time of WLE may improve the reliability of complete excision. Within the past 15 years, the local recurrence rate after WLE has slightly declined (11\%-36\%) for ocular SC. This may be due to the increased clinical awareness of SC, leading to an overall earlier stage at diagnosis. ${ }^{7,16,50,51}$ Among patients who underwent excision with $5 \mathrm{~mm}$ surgical margins and paraffin section pathologic analysis, involvement of both eyelids, topical treatments at other clinics, multicentric origin, diffuse pattern, stage T3a, large tumor size, and a nonlobular pattern significantly influenced local recurrence and metastasis. ${ }^{7,16,28,45,50,51}$ In general, recurrent disease is treated with surgical re-excision. It must be mentioned that in any patient with corneal involvement, incisional cataract surgery should be avoided because disruption of the Bowman membrane may seed carcinomatous cells into the eye. ${ }^{26}$

Well-designed reconstruction with a flap from neighboring tissue needs to be performed after WLE to restore eyelid function and aesthetics. Despite traditional 2-staged reconstructive surgical methods, a single-staged procedure has also shown optimal outcomes..$^{38,52}$

\section{Radiation therapy}

Radiation therapy, especially brachytherapy, has been proven as an efficient treatment of ocular SC, facilitating functional and cosmetic preservation of the eyelid with good

Table 2 Sources of 39 patients with ocular SC treated by MMS

\begin{tabular}{|c|c|c|c|c|c|}
\hline Reference & $\begin{array}{l}\text { Number } \\
\text { of patients }\end{array}$ & Location & $\begin{array}{l}\text { Local recurrence or } \\
\text { metastasis }\end{array}$ & Subsequent treatment & $\begin{array}{l}\text { Mean follow-up } \\
\text { period, months }\end{array}$ \\
\hline Spencer et $\mathrm{al}^{28}$ & 18 & Ocular & $\begin{array}{l}\text { One recurrence and pagetoid } \\
\text { metastasis at } 9 \text { months } \\
\text { One recurrence at } 19 \text { months }\end{array}$ & $\begin{array}{l}\text { Exenteration and parotid/neck } \\
\text { dissection } \\
\text { Not mentioned }\end{array}$ & 37 \\
\hline Snow et $\mathrm{al}^{44}$ & 9 & Ocular & $\begin{array}{l}\text { One recurrence and lymph } \\
\text { node metastasis at } 1.5 \text { years }\end{array}$ & Exenteration & 38.4 \\
\hline Callahan et $\mathrm{al}^{45}$ & 2 & Ocular & One recurrence at 71 months & $\begin{array}{l}\text { Exenteration, total parotidectomy, } \\
\text { and cervical node dissection }\end{array}$ & 57 \\
\hline Arora et $\mathrm{al}^{46}$ & 1 & Ocular & No recurrence & & 36 \\
\hline Thomas et $\mathrm{al}^{47}$ & 3 & Ocular and extraocular & No recurrence & & 10.7 \\
\hline Brady and Hurst ${ }^{48}$ & 6 & Ocular & No recurrence & & 43.2 \\
\hline
\end{tabular}

Abbreviations: MMS, Mohs micrographic surgery; SC, sebaceous carcinoma. 
local control and acceptable toxicity. However, the tumor is generally regarded as resistant to radiation therapy, and high recurrence rates have been reported. ${ }^{10,17,53}$ Radiation is only employed as adjuvant treatment for locally advanced (stage T3a or higher) or high-risk (pagetoid spread) periorbital SC, ${ }^{49,54,55}$ perineural invasion, nodal metastasis, or palliative treatment. ${ }^{55,56}$

To date, numerous case series and case reports have demonstrated a response to radiation therapy in patients who were either poor surgical candidates or who refused surgical treatment. In a study of 13 patients with T3 SC, the local recurrence rate was lower among those who received adjuvant radiotherapy (28\%) than among those who did not $(83.3 \%) .{ }^{57}$ Complications from radiotherapy can be quite extensive and include chronic dry eye, conjunctival keratinization, blepharitis, trichiasis, exposure keratopathy, cataract, optic neuropathy, retinopathy, and even permanent loss of visual acuity. ${ }^{49,56}$ The risk should be minimized with appropriate shielding and balanced against the obvious morbidity of orbital exenteration.

\section{Cryotherapy and topical chemotherapy}

Cryotherapy and topical chemotherapy (mitomycin C) have a certain effect on ocular SC with pagetoid spread to the conjunctiva or cornea. ${ }^{58}$ For elderly patients who prefer more conservative approaches, they seem to be feasible choices.

In a retrospective case series identifying predictors of ocular surface squamous neoplasm recurrence after surgical resection, the addition of cryotherapy to the margins and scleral bed has been shown to dramatically reduce recurrence rates, ${ }^{59}$ which may be significant in ocular SC. The side effects of cryotherapy include permanent loss of visual acuity, corneal ulceration, and chronic dry eye. The use of this method is somewhat controversial and is largely surgeon dependent at this point. ${ }^{49}$ Topical chemotherapy has been used as adjuvant therapy for residual SC in situ. Topical mitomycin C $0.04 \% 4$ times a day for 1 week on and 1 week off has induced clinical tumor regression after 3 cycles in 1 patient and 4 cycles in 2 patients. ${ }^{27,58}$ This pilot study ${ }^{58}$ demonstrated complete clearing of intraepithelial pagetoid invasion after topical application of mitomycin $\mathrm{C}$.

\section{Targeted therapy}

In recent years, targeted therapy has had an emerging role in the treatment of refractory tumors, such as advanced melanoma ${ }^{60}$ For patients with metastatic or locally advanced BCC or SCC, targeted therapy against the Hedgehog pathway or epidermal growth factor receptor has been shown to be fairly efficacious in preventing disease progression. ${ }^{30,61}$ In a series of current studies, an overexpression of HER2 is observed in $\mathrm{SC},{ }^{23,62}$ thus suggesting the possibility of targeted therapy with monoclonal antibodies trastuzumab and cetuximab. ${ }^{61}$ Confirmation of frequent PI3K signaling pathway activation provides a strong rationale for the application of mammalian target of rapamycin inhibitors in targeted therapy of ocular SC. ${ }^{25}$

\section{The management of metastasis}

Up to $25 \%$ of SCs metastasize.${ }^{17}$ For lymph node and distant metastases, combination treatments, including lymph node and neck dissection, radiation therapy, and systemic chemotherapy, should be considered..$^{61,63,64}$

Two case reports on the management of recurrent, locally advanced, or metastatic SC of the eyelids showed neoadjuvant cisplatin and fluorouracil for 1 cycle in 1 case report and carboplatin and 5-fluorouracil for 3 cycles in the other with favorable responses and stable residual disease. ${ }^{63}$ Neoadjuvant chemotherapy may enable local resection of advanced tumors, thus avoiding disfiguring procedures, such as exenteration. ${ }^{64,65}$

Orbital exenteration refers to a surgical procedure involving removal of the eyeball and intraorbital contents. This morbific surgery is usually reserved for SC that involves most of the conjunctiva and has invaded the orbit or for potentially life-threatening SC. ${ }^{66-68}$ Gerring et $\mathrm{al}^{67}$ demonstrated that orbital exenteration offered a 2-year mean disease-free survival of $39.2 \%$ among advanced SC cases.

\section{Prognosis}

In the past, ocular SC has led to cancer-specific mortality in $\sim 18 \%-30 \%$ of patients. ${ }^{17,69}$ Fortunately, more attention has been paid to this tumor, and the mortality has decreased to $3 \%-7.3 \%$ due to comprehensive therapy. ${ }^{6,10,12,50}$

The indicators for prognosis have been disputed. On the basis of a retrospective study, the T category was significantly associated with lymph node metastasis and disease-specific survival, especially among patients with a $\mathrm{T}$ category of T3a or worse. ${ }^{27}$ Orbital involvement was once considered to be associated with worsened prognosis, while it has been challenged in a contemporary retrospective review of 1,394 cases of SC. ${ }^{1}$ Other histological markers of poor prognosis in previous reports include pagetoid spread, multicentric origin, tumor size $>10 \mathrm{~mm}$, tumor growth pattern, ${ }^{16}$ and invasion of vascular, lymphatic, and perineural structures. In addition, other poor prognostic indicators consist of delayed diagnosis ( $>6$ months), involvement of 
both eyelids, ${ }^{27}$ and the presence of metastatic disease at the time of diagnosis. ${ }^{4}$ However, Takahashi et $\mathrm{al}^{16}$ found that the interval between the appearance of symptoms and referral to medical center did not significantly affect local recurrence or metastasis. Different patient characteristics may provide a possible explanation.

Compared to traditional isolated risk factors, the development of a new model for individualized prediction of tumor-related survival may pave the way for prognostic stratification.

\section{Conclusion}

Ocular SC is an uncommon, but aggressive malignancy with great potential to spread to regional lymph nodes and beyond. As its clinical presentation is nonspecific, definite diagnosis of this tumor relies on histopathologic confirmation, which can be challenging. Special efforts should be made to unveil the mechanism of ocular SC in order to provide evidence for targeted therapy. The existing literature related to the treatment of ocular SC primarily consists of small- to mediumsized case series and isolated case reports, impeding the possibility to reach a clinical consensus. As a result, surgical excision with a tumor-free margin continues to be the best choice for ocular SC that is discovered early. Adjuvant treatment options, including radiation therapy, cryotherapy, and topical therapy are adapted based on the extent of the tumor. Larger studies with longer follow-up periods are essential for clarifying the long-term effects of different treatment modalities. For the management of late-stage cases, multicenter clinical trials may be an appropriate solution to accrue adequate patient numbers. Patients with ocular SC require long-term follow-up with careful clinical examination for at least 5 years after radical antitumor therapy, regardless of tumor stage or anatomic location.

\section{Acknowledgments}

This work was supported by the Scientific Research Program of National Health and Family Planning Commission of China (201402014), the Science and Technology Commission of Shanghai (17DZ2260100) and the National Natural Science Foundation of China (Grant No 81500757).

\section{Author contributions}

$\mathrm{RBJ}$ and $\mathrm{XQF}$ are senior authors on this paper. YFX prepared the first draft of the manuscript; FL contributed to the design and writing of the manuscript. RBJ and $\mathrm{XQF}$ critically reviewed and revised the manuscript. All authors read and approved the final manuscript. All authors contributed toward data acquisition and analysis, drafting and critically revising the paper and agree to be accountable for all aspects of the work.

\section{Disclosure}

The authors report no conflicts of interest in this work.

\section{References}

1. Dasgupta T, Wilson LD, Yu JB. A retrospective review of 1,349 cases of sebaceous carcinoma. Cancer. 2009;115(1):158-165.

2. Kuzel P, Metelitsa AI, Dover DC, Salopek TG. Epidemiology of sebaceous carcinoma in Alberta, Canada, from 1988 to 2007. J Cutan Med Surg. 2012;16(6):417-423.

3. Dores GM, Curtis RE, Toro JR, Devesa SS, Fraumeni JF Jr. Incidence of cutaneous sebaceous carcinoma and risk of associated neoplasms: insight into Muir-Torre syndrome. Cancer. 2008;113(12):3372-3381.

4. Tryggvason G, Bayon R, Pagedar NA. Epidemiology of sebaceous carcinoma of the head and neck: implications for lymph node management. Head Neck. 2012;34(12):1765-1768.

5. Shields JA, Saktanasate J, Lally SE, Carrasco JR, Shields CL. Sebaceous carcinoma of the ocular region: the 2014 Professor Winifred Mao lecture. Asia Pac J Ophthalmol. 2015;4(4):221-227.

6. Tripathi R, Chen Z, Li L, Bordeaux JS. Incidence and survival of sebaceous carcinoma in the United States. $J$ Am Acad Dermatol. 2016; 75(6):1210-1215.

7. Shields JA, Demirci H, Marr BP, Eagle RC Jr, Shields CL. Sebaceous carcinoma of the ocular region: a review. Surv Ophthalmol. 2005; 50(2):103-122.

8. Lin HY, Cheng CY, Hsu WM, Kao WH, Chou P. Incidence of eyelid cancers in Taiwan: a 21-year review. Ophthalmology. 2006;113(11):2101-2107.

9. Muqit MM, Foot B, Walters SJ, Mudhar HS, Roberts F, Rennie IG. Observational prospective cohort study of patients with newly-diagnosed ocular sebaceous carcinoma. Br J Ophthalmol. 2013;97(1):47-51.

10. Shields JA, Demirci H, Marr BP, Eagle RC Jr, Shields CL. Sebaceous carcinoma of the eyelids: personal experience with 60 cases. Ophthalmology. 2004;111(12):2151-2157.

11. Pe'er J. Pathology of eyelid tumors. Indian J Ophthalmol. 2016;64(3): 177-190.

12. Song A, Carter KD, Syed NA, Song J, Nerad JA. Sebaceous cell carcinoma of the ocular adnexa: clinical presentations, histopathology, and outcomes. Ophthal Plast Reconstr Surg. 2008;24(3):194-200.

13. Mahipathy SR, Durairaj AR, Kothandaraman K, Rajamanohar VC, Prabakaran A. Sebaceous gland carcinoma of the lower eyelid reconstructed with a composite flap: a case report. J Clin Diagn Res. 2016; 10(6):PD16-PD18.

14. Bernardini FP. Management of malignant and benign eyelid lesions. Curr Opin Ophthalmol. 2006;17(5):480-484.

15. Kiratli H, Tarlan B, Firat P. Primary sebaceous carcinoma of the lacrimal gland. Orbit. 2012;31(5):352-354.

16. Takahashi Y, Takahashi E, Nakakura S, Kitaguchi Y, Mupas-Uy J, Kakizaki H. Risk factors for local recurrence or metastasis of eyelid sebaceous gland carcinoma after wide excision with paraffin section control. Am J Ophthalmol. 2016;171:67-74.

17. Slutsky JB, Jones EC. Periocular cutaneous malignancies: a review of the literature. Dermatol Surg. 2012;38(4):552-569.

18. Stockl FA, Dolmetsch AM, Codere F, Burnier MN Jr. Sebaceous carcinoma of the eyelid in an immunocompromised patient with Muir-Torre syndrome. Can J Ophthalmol. 1995;30(6):324-326.

19. Hoss E, Nelson SA, Sharma A. Sebaceous carcinoma in solid organ transplant recipients. Int J Dermatol. 2017;56(7):746-749.

20. Kaliki S, Ayyar A, Dave TV, Ali MJ, Mishra DK, Naik MN. Sebaceous gland carcinoma of the eyelid: clinicopathological features and outcome in Asian Indians. Eye. 2015;29(7):958-963. 
21. Bell WR, Singh K, Rajan Kd A, Eberhart CG. Expression of p16 and p53 in intraepithelial periocular sebaceous carcinoma. Ocul Oncol Pathol. 2015;2(2):71-75.

22. Kiyosaki K, Nakada C, Hijiya N, et al. Analysis of p53 mutations and the expression of $\mathrm{p} 53$ and $\mathrm{p} 21 \mathrm{WAF} 1 / \mathrm{CIP} 1$ protein in 15 cases of sebaceous carcinoma of the eyelid. Invest Ophthalmol Vis Sci. 2010;51(1):7-11.

23. Kwon MJ, Shin HS, Nam ES, et al. Comparison of HER2 gene amplification and KRAS alteration in eyelid sebaceous carcinomas with that in other eyelid tumors. Pathol Res Pract. 2015;211(5): 349-355.

24. Liau JY, Liao SL, Hsiao CH, Lin MC, Chang HC, Kuo KT. Hypermethylation of the CDKN2A gene promoter is a frequent epigenetic change in periocular sebaceous carcinoma and is associated with younger patient age. Hum Pathol. 2014;45(3):533-539.

25. Tetzlaff MT, Singh RR, Seviour EG, et al. Next-generation sequencing identifies high frequency of mutations in potentially clinically actionable genes in sebaceous carcinoma. J Pathol. 2016;240(1):84-95.

26. Yang PT, Tucker NA, Rootman DB, Rootman DS, McGowan H, Chan CC. Pagetoid spread of sebaceous cell carcinoma to the cornea. Can J Ophthalmol. 2012;47(6):e46-e47.

27. Esmaeli B, Nasser QJ, Cruz H, Fellman M, Warneke CL, Ivan D. American Joint Committee on Cancer $\mathrm{T}$ category for eyelid sebaceous carcinoma correlates with nodal metastasis and survival. Ophthalmology. 2012;119(5):1078-1082.

28. Spencer JM, Nossa R, Tse DT, Sequeira M. Sebaceous carcinoma of the eyelid treated with Mohs micrographic surgery. $J$ Am Acad Dermatol. 2001;44(6):1004-1009.

29. Chao AN, Shields CL, Krema H, Shields JA. Outcome of patients with periocular sebaceous gland carcinoma with and without conjunctival intraepithelial invasion. Ophthalmology. 2001;108(10):1877-1883.

30. Yin VT, Merritt HA, Sniegowski M, Esmaeli B. Eyelid and ocular surface carcinoma: diagnosis and management. Clin Dermatol. 2015; 33(2):159-169.

31. Ha A, Kim N. Sebaceous gland carcinoma of tarsus can be misdiagnosed as intratarsal keratinous cyst. Can J Ophthalmol. 2016;51(3): e99-e101.

32. Jayaraj P, Sen S, Bhattacharya T, et al. Clinical relevance of cyclooxygenase 2 and peroxisome proliferator-activated receptor gamma in eyelid sebaceous gland carcinoma. Histopathology. 2016;69(2):268-275.

33. Schmitz EJ, Herwig-Carl MC, Holz FG, Loeffler KU. Sebaceous gland carcinoma of the ocular adnexa - variability in clinical and histological appearance with analysis of immunohistochemical staining patterns. Graefes Arch Clin Exp Ophthalmol. 2017;255(11):2277-2285.

34. Cabral ES, Auerbach A, Killian JK, Barrett TL, Cassarino DS. Distinction of benign sebaceous proliferations from sebaceous carcinomas by immunohistochemistry. Am J Dermatopathol. 2006;28(6):465-471.

35. Na HY, Choe JY, Shin SA, et al. Proposal of a provisional classification of sebaceous carcinoma based on hormone receptor expression and HER2 status. Am J Surg Pathol. 2016;40(12):1622-1630.

36. Ostler DA, Prieto VG, Reed JA, Deavers MT, Lazar AJ, Ivan D. Adipophilin expression in sebaceous tumors and other cutaneous lesions with clear cell histology: an immunohistochemical study of 117 cases. Mod Pathol. 2010;23(4):567-573.

37. While B, Salvi S, Currie Z, Mudhar HS, Tan JH. Excision and delayed reconstruction with paraffin section histopathological analysis for periocular sebaceous carcinoma. Ophthal Plast Reconstr Surg. 2014; 30(2):105-109.

38. Chang HH, Suh E, Fortes BH, Zheng F, Cheng AM. Forehead galeal pericranial flap for single-staged total upper eyelid reconstruction in sebaceous gland carcinoma excision. Int Med Case Rep J. 2017;10: 309-312.

39. Savar A, Oellers P, Myers J, et al. Positive sentinel node in sebaceous carcinoma of the eyelid. Ophthal Plast Reconstr Surg. 2011; 27(1):e4-e6.

40. Nijhawan N, Ross MI, Diba R, Ahmadi MA, Esmaeli B. Experience with sentinel lymph node biopsy for eyelid and conjunctival malignancies at a cancer center. Ophthal Plast Reconstr Surg. 2004;20(4):291-295.
41. Kingham TP, Panageas KS, Ariyan CE, Busam KJ, Brady MS, Coit DG. Outcome of patients with a positive sentinel lymph node who do not undergo completion lymphadenectomy. Ann Surg Oncol. 2010;17(2): 514-520.

42. Knackstedt T, Samie FH. Sebaceous carcinoma: a review of the scientific literature. Curr Treat Options Oncol. 2017;18(8):47.

43. Tolkachjov SN. Adnexal carcinomas treated with Mohs micrographic surgery: a comprehensive review. Dermatol Surg. 2017;43(10): 1199-1207.

44. Snow SN, Larson PO, Lucarelli MJ, Lemke BN, Madjar DD. Sebaceous carcinoma of the eyelids treated by mohs micrographic surgery: report of nine cases with review of the literature. Dermatol Surg. 2002;28(7):623-631.

45. Callahan EF, Appert DL, Roenigk RK, Bartley GB. Sebaceous carcinoma of the eyelid: a review of 14 cases. Dermatol Surg. 2004;30(8): $1164-1168$.

46. Arora A, Barlow RJ, Williamson JM, Olver JM. Eyelid sebaceous gland carcinoma (SGC) treated with "slow" Mohs' micrographic surgery. Eye. 2004;18(8):854-855.

47. Thomas CJ, Wood GC, Marks VJ. Mohs micrographic surgery in the treatment of rare aggressive cutaneous tumors: the Geisinger experience. Dermatol Surg. 2007;33(3):333-339.

48. Brady KL, Hurst EA. Sebaceous carcinoma treated with Mohs micrographic surgery. Dermatol Surg. 2017;43(2):281-286.

49. Kyllo RL, Brady KL, Hurst EA. Sebaceous carcinoma: review of the literature. Dermatol Surg. 2015;41(1):1-15.

50. Erovic BM, Goldstein DP, Kim D, et al. Sebaceous gland carcinoma of the head and neck: the Princess Margaret Hospital experience. Head Neck. 2013;35(3):316-320.

51. Dowd MB, Kumar RJ, Sharma R, Murali R. Diagnosis and management of sebaceous carcinoma: an Australian experience. ANZ J Surg. 2008;78(3):158-163.

52. Pushker N, Batra J, Meel R, Bajaj MS, Chawla B, Ghose S. Lateral eyelid rotation flap: a novel technique for reconstruction of full thickness eyelid defect. Int Ophthalmol. 2015;35(6):793-799.

53. Belaid A, Nasr C, Benna M, et al. Radiation therapy for primary eyelid cancers in Tunisia. Asian Pac J Cancer Prev. 2016;17(7): 3643-3646.

54. Connor M, Droll L, Ivan D, et al. Management of perineural invasion in sebaceous carcinoma of the eyelid. Ophthal Plast Reconstr Surg. 2011;27(5):356-359.

55. Deo SV, Shukla NK, Singh M, Jha D, Khanna P, Kallianpur A. Locally advanced sebaceous cell carcinoma (T3) of eyelid: incidence and pattern of nodal metastases and combined modality management approach. Orbit. 2012;31(3):150-154.

56. Hsu A, Frank SJ, Ballo MT, et al. Postoperative adjuvant external-beam radiation therapy for cancers of the eyelid and conjunctiva. Ophthal Plast Reconstr Surg. 2008;24(6):444-449.

57. Hata M, Koike I, Omura M, Maegawa J, Ogino I, Inoue T. Noninvasive and curative radiation therapy for sebaceous carcinoma of the eyelid. Int J Radiat Oncol Biol Phys. 2012;82(2):605-611.

58. Shields CL, Naseripour M, Shields JA, Eagle RC Jr. Topical mitomycin-C for pagetoid invasion of the conjunctiva by eyelid sebaceous gland carcinoma. Ophthalmology. 2002;109(11):2129-2133.

59. Galor A, Karp CL, Oellers P, et al. Predictors of ocular surface squamous neoplasia recurrence after excisional surgery. Ophthalmology. 2012; 119(10):1974-1981.

60. Ribas A, Hamid O, Daud A, et al. Association of pembrolizumab with tumor response and survival among patients with advanced melanoma. JAMA. 2016;315(15):1600-1609.

61. Della Vittoria Scarpati G, Perri F, Pisconti S, et al. Concomitant cetuximab and radiation therapy: a possible promising strategy for locally advanced inoperable non-melanoma skin carcinomas. Mol Clin Oncol. 2016;4(4):467-471.

62. Cho KJ, Khang SK, Koh JS, Chung JH, Lee SS. Sebaceous carcinoma of the eyelids: frequent expression of c-erbB-2 oncoprotein. $J$ Korean Med Sci. 2000;15(5):545-550. 
63. Priyadarshini O, Biswas G, Biswas S, Padhi R, Rath S. Neoadjuvant chemotherapy in recurrent sebaceous carcinoma of eyelid with orbital invasion and regional lymphadenopathy. Ophthal Plast Reconstr Surg. 2010;26(5):366-368.

64. Gogia A, Pushker N, Sen S, Bakhshi S. Avoidance of exenteration in orbital sebaceous gland carcinoma with neoadjuvant chemotherapy. Graefes Arch Clin Exp Ophthalmol. 2013;251(10):2479-2480.

65. Kaliki S, Ayyar A, Nair AG, Mishra DK, Reddy VA, Naik MN. Neoadjuvant systemic chemotherapy in the management of extensive eyelid sebaceous gland carcinoma: a study of 10 cases. Ophthal Plast Reconstr Surg. 2016;32(1):35-39.

66. Shields JA, Shields CL, Demirci H, Honavar SG, Singh AD. Experience with eyelid-sparing orbital exenteration: the 2000 Tullos O. Coston lecture. Ophthal Plast Reconstr Surg. 2001;17(5):355-361.
67. Gerring RC, Ott CT, Curry JM, Sargi ZB, Wester ST. Orbital exenteration for advanced periorbital non-melanoma skin cancer: prognostic factors and survival. Eye. 2017;31(3):379-388.

68. Ali MJ, Pujari A, Dave TV, Kaliki S, Naik MN. Clinicopathological profile of orbital exenteration: 14 years of experience from a tertiary eye care center in South India. Int Ophthalmol. 2016;36(2):253-258.

69. Sinard JH. Immunohistochemical distinction of ocular sebaceous carcinoma from basal cell and squamous cell carcinoma. Arch Ophthalmol. 1999;117(6):776-783.

\section{Publish your work in this journal}

OncoTargets and Therapy is an international, peer-reviewed, open access journal focusing on the pathological basis of all cancers, potential targets for therapy and treatment protocols employed to improve the management of cancer patients. The journal also focuses on the impact of management programs and new therapeutic agents and protocols on

\section{Dovepress}

patient perspectives such as quality of life, adherence and satisfaction. The manuscript management system is completely online and includes a very quick and fair peer-review system, which is all easy to use. Visit http://www.dovepress.com/testimonials.php to read real quotes from published authors. 